\title{
0 Manejo da Cidadania e a Democracia do Cuidado
}

Lecy Sartori

(UFSCAR)

\section{APRESENTAÇÃ 0}

O Centro de Atenção Psicossocial (CAPS) ${ }^{1}$ Esperança foi criado, em 2003, por trabalhadores do Serviço de Saúde Cândido Ferreira². A assistência ambulatorial foi inicialmente experimentada pela equipe do Hospital-Dia (HD), ainda no âmbito da referida instituição filantrópica, em Sousas. O HD foi criado em 1991 após a formalização do projeto de cogestão $o^{3}$ com a Prefeitura Municipal de Campinas, assinado em maio de 1990. A experiência de criação de uma nova instituição como o HD permitiu aos profissionais (o que denomino de profissionais, técnicos ou interlocutores são as pessoas que trabalham no CAPS Esperança) apostarem (ou acreditarem) no projeto de um CAPS inserido no território ou comunidade. Assim, surgiu o CAPS Esperança, que além da assistência realizada durante o dia, também possui os leitos noite para internações de curto prazo, visando aos pacientes ${ }^{4}$ já conhecidos e tratados pela equipe de profissionais.

O CAPS Esperança era responsável pelo atendimento de cerca de 280 pacientes (ou usuários). Estes últimos são classificados de acordo com a frequência com que iam à instituição: pacientes intensivos (frequentam a instituição até 25 dias por mês), semi-intensivos (até 12 dias ao mês) e pacientes não intensivos (3 dias ao mês) (Brasil 2002). A instituição atendia em média 90 pacientes ao dia, a maioria deles intensivos. Os pacientes eram diagnosticados como "psicóticos e alguns poucos como neuróticos graves", segundo a médica psiquiátrica do CAPS.

O processo de reformulação da assistência em saúde mental ocorreu a partir dos questionamentos da Reforma Psiquiátrica Brasileira (RPB) ${ }^{5}$, que teve seu estopim no final da década de 1970, com o Movimento dos Trabalhadores de Saúde Mental (MTSM). As experiências concretas, no entanto, só puderam ser visualizadas nos serviços públicos na década seguinte com a criação do primeiro CAPS (denominado Luiz Cerqueira), em São Paulo. A RPB constituiu um processo 
histórico de questionamento e de reformulação das práticas psiquiátricas, com o objetivo de elaborar um novo modelo de atenção psicossocial e a inserção do paciente em uma rede de relações sociais. Na década de 1990, o processo da reforma no modelo de assistência transformou o hospital psiquiátrico Cândido Ferreira em uma Rede de instituições regionalizadas. Essa configuração em rede tem por estratégia de ação disponibilizar a assistência psiquiátrica a um determinado território e, desse modo, tratar uma população de risco a partir do controle na própria comunidade, ao invés de retirar o paciente do seu espaço de relações para tratá-lo no interior de um espaço hospitalar.

O CAPS Esperança está localizado no distrito leste de Campinas. Para os profissionais dessa instituição, somente o paciente é capaz de elaborar um saber acerca do que ele sente e vive como experiência. Ao exercer a clínica, os técnicos procuram responsabilizar (ou comprometer) o usuário com o seu cuidado (tratamento). Isso implica em uma inversão da posição de passividade (dos pacientes) para uma posição de sujeito atuante no seu processo terapêutico. Como aponta Silva (2005), as práticas de responsabilização dos sujeitos por seus sintomas e sofrimentos fazem parte do próprio processo terapêutico que permite aos usuários abandonarem a situação de vítima de uma ciência médica. De acordo com os profissionais: "o sofrimento indica o caminho para cuidar do paciente". Ou seja, caminhos para a elaboração de intervenções que procuram ajudar o paciente a minimizar os seus sofrimentos, a evitar as crises e possíveis internações psiquiátricas. É na superação do conceito de doença que os profissionais colocam em funcionamento uma nova tecnologia que considera o sofrimento como parte constitutiva da complexidade dos sujeitos. A relação terapêutica, pautada na complexidade do sujeito, não procura mais a cura da doença ou explicações orgânicas para o sofrimento. A cura é um processo contínuo de produção de vida, de invenção de saúde, de subjetividade, de cidadania, de relações sociais e de vínculos.

Nesse caso, em particular, a afirmação de vida está diretamente relacionada com a construção do Projeto Terapêutico Individual (PTI). A responsabilização e a participação ativa do paciente na elaboração de seu tratamento permitem que ele saia do espaço asilar e se reúna em grupos para solicitar, por meio das políticas públicas, seus direitos. Assim, pode-se observar uma transformação na qual operam mecanismos positivos de poder que incidem sobre a vida e suas potencialidades particulares, estimuladas pela equipe técnica. De fato, os profissionais modificaram o tratamento que, antes, buscava a cura da doença para o uso de uma nova tecnologia que problematiza a existência e promove a saúde, que já não é de única responsabilidade do médico. Promove-se, ao mesmo tempo, um novo tipo de controle sobre os sujeitos, que deixa de ser apenas disciplinar - como já apontavam as análises de Foucault (2002: 123), na década de 70, sobre a mudança no regime de dominação disciplinar (apud Deleuze 2007a: 219) - para exigir sua participação por meio de um pacto democrático (Passetti 2003: 228) que deve ser continuamente negociado em suas atuações no interior das políticas públicas e da política institucional.

Ao escolher uma instituição psiquiátrica como objeto empírico, pesquisei sobre as diferentes abordagens elaboradas pela disciplina da antropologia da saúde (Cardoso 1999, 2002; Lougon 1987; Venâncio 1990; Perelberg 1980), em especial os estudos que articulavam a experiência de saúde e doença com as grandes teorias antropológicas sobre indivíduo e pessoa (Duarte 1980, 1994, 2000). Em minha análise, procurei expor como os 
profissionais elaboram suas práticas de cuidados de forma democrática, ou seja, de forma que respeite todos aqueles que participam da invenção das soluções adequadas para os problemas vividos no cotidiano institucional. Ao enfatizar a sua potência inventiva, registrando e descrevendo, assim, as particularidades do seu contexto, pude ir "além dos pressupostos universalizadores, (visto que) a etnografia pode trazer a público os cálculos e interações [...], além de iluminar rumos alternativos abertos por novos desejos" (Biehl 2008: 423). Cabe destacar que optei pela abordagem da antropologia política, a qual me permite investigar e enfatizar, por meio dos enunciados nativos, que existe uma produção histórica que pode ser reconhecida pelas novas práticas e pela invenção de outros saberes. Dito de outra forma, creio que essa perspectiva me possibilita conferir inteligibilidade aos conceitos e as teorias dos profissionais do CAPS Esperança em suas mediações com sua experiência social (Villela 2010a: 20, 2010b: 170; Biondi 2010: 24). Pretende-se, assim, evitar que a teoria sobreponha a multiplicidade que existe na invenção das práticas democráticas.

\section{A CLÍNICA DAS RELAÇÕES}

Iniciei minha pesquisa de campo em fevereiro de 2008. Por cinco meses estive em contato tanto com os pacientes atendidos pela instituição quanto com os profissionais que ali trabalhavam. A relação estabelecida com os profissionais permitiu entender como eles experimentavam suas práticas e como significavam sua realidade. Essa forma de interação se aproxima da experiência de Favret-Saada (2005), que ao analisar a feitiçaria no Bocage francês, fez de sua participação na experiência de campo um instrumento de conhecimento ao permitir-se envolver por eventos e intensidades específicas (que a autora chama de afetos). Portanto, não se trata aqui de importar um conceito como modelo teórico explicativo, mas antes de me ater às construções conceituais produzidas pelos profissionais para explicar suas práticas e o contexto em que elas estão inseridas (Strathern 2011: 33).

O objetivo central deste artigo é explicitar os discursos que acessei por meio do perspectivismo e do ponto de vista dos profissionais, para pontuar como a mudança no modelo de assistência à saúde mental se configura atualmente no CAPS Esperança. Assim o fez Paul Veyne (2001: 82-83), quando afirmou extrair dos discursos os fatos da vida cotidiana que colocam à prova, o tempo todo, os modos de agir e consentir. Ou ainda, para citar o que Villela (2004: 22) escreveu em sua etnografia: "O que chamo de perspectivismo e ponto de vista aproxima-se dos conceitos de sentido e interpretação em Nietzsche". Para Nietzsche, o acontecimento possibilita reinterpretar um fenômeno redirecionando-o para uma nova finalidade, o que permite subjugar e ajustar o sentido em uma nova interpretação (2004: 66) - aqui entendida como o exercício de fixar o sentido ao fenômeno (Deleuze 2007b: 17). Ao descrever os discursos a partir das experiências vividas pelos atores, procuro (como sugeriu Goldman 2006: 41) defini-los como um dispositivo histórico que me permite articular e refletir sobre a invenção de uma nova tecnologia de cuidado. 
No CAPS Esperança, foi-me permitido o acesso às atividades que aconteciam em equipe e com os pacientes: por um lado, o trabalho coletivo (ou em grupo) produzido em espaços como a reunião de equipe, a reunião de miniequipe ${ }^{6}$, o grupo de estudo (reunião dedicada à leitura de textos) e a supervisão clínica e institucional (respectivamente, dedicada à discussão de um caso clínico e aos problemas institucionais); por outro lado, as atividades de que participavam profissionais e pacientes - como a assembleia, o grupo de tratamento, o acolhimento, a triagem, a consulta médica, o atendimento individual, as oficinas, o acompanhamento terapêutico $(A T)$, as visitas domiciliares (visita à residência do paciente) e a reunião de matriciamento (espaço de discussão de casos clínicos que transitavam entre o CAPS e o Posto de Saúde). É nesses espaços institucionais que os profissionais e os pacientes produzem vínculos (Dias 2007; Sartori 2010; Silva 2005, 2007, 2009; Monnerat 2009, 2010). Havia ainda ali a circulação de informações, o atravessamento de relações de forças e determinados interesses que eram constantemente articulados, atualizados e negociados. Além disso, os espaços coletivos possibilitavam aos profissionais observar cada usuário, detectar possíveis demandas não pronunciadas, operar a escuta terapêutica, encaminhar para a consulta médica ou para os procedimentos da enfermagem (por exemplo, verificar a pressão e tomar medicação), discutir o cotidiano do CAPS, falar do que os incomodava, dar sugestões de mudanças (que podia ser referente ao espaço físico do CAPS ou até mesmo sobre sua forma de funcionamento e organização), formular regras institucionais (como a proibição do ato de fumar cigarro no interior da casa) e combinar acordos coletivos. Do mesmo modo, as relações terapêuticas eram pensadas, avaliadas e formuladas por práticas democráticas (conforme afirmou uma psicóloga do CAPS). Nas palavras de uma enfermeira, as práticas democráticas são aquelas que "respeitam os sujeitos portadores de direito, não somente os pacientes, mas todos aqueles que participam da instituição". Nesse sentido, elas são, antes de tudo, uma relação, e incitam a participação política.

Sabe-se que na década de 1950, os estudos da antropologia processualista (que criticaram a antropologia estrutural-funcionalista) afirmaram ser a política um aspecto de qualquer relação social. Essa nova abordagem analisou, ao invés da instabilidade dos sistemas políticos, as mudanças, os conflitos, as tensões, enfim, as redes de relações e os diferentes tipos de conexões interindividuais. Essa perspectiva considerou os grupos como um processo dinâmico, que possibilitava ao ator interferir nas mudanças ocorridas (Lienhardt 1958). Assim, a política foi vista como ação, e as relações de poder eram acionadas pelos interesses e objetivos que as pessoas procuravam alcançar (Swartz et al. 1966). Autores como Balandier (1969: 25) já apontaram para os perigos de reduzir todas as dimensões sociais (parentesco, religião e economia) ao político. Desse modo, os estudos da antropologia da política, feitos no Brasil a partir da década de 1990, investigaram os fenômenos políticos a partir do "ponto de vista nativo, aquilo que pode ser definido como política está sempre em relação com o restante das experiências vividas pelos agentes" (Goldman 2006: 41).

Essa abordagem permite apreender as teorias nativas em ato, isto é, em seu contexto, segundo a forma de atualização de suas práticas, de seus saberes e de suas experiências (Palmeira 1992, 1996; Chaves 2003; Goldman 2006; Marques 2002, 2003; Villela 2009). Os desdobramentos de uma nova configuração da assistência psiquiátrica provocaram efeitos nas relações de poder e de controle, que entrou em crise no pós-Segunda Guerra Mundial. 
As novas forças reformadoras do regime de confinamento emergiram progressivamente. Surgiram, então, as "sociedades de controle" - caracterizadas, principalmente, por um controle automodulado que se ajusta de forma contínua aos sujeitos em espaços abertos, ao invés de grandes instituições de confinamento. Os indivíduos tornaram-se sujeitos híbridos ou dividuais, e a formação contínua substituiu a serialização das disciplinas (Deleuze 2007a: 220). Para Foucault (2010: 317), a característica principal dessa nova racionalidade política está na integração dos sujeitos em um grupo (ou comunidade), que se consolida continuamente pelo processo de individualização.

O processo de individualização é fabricado na clínica psiquiátrica a partir das explicações que cada paciente elabora sobre o seu mal estar. Para os profissionais de saúde investigados, a clínica é tudo aquilo que se apreende na relação com o paciente. Essa operação clínica desloca a assistência do campo da significação anatomopatológica para a explicação dos sintomas apresentados no discurso do paciente (suas queixas). Ou como afirmavam os profissionais: a clínica promove o "aparecimento dos sujeitos". Nas práticas de cuidado são utilizadas estratégias técnico-institucionais para produzir sujeitos autônomos que podem circular de forma independente pela cidade (ir para a casa, receber o dinheiro do seu benefício na agência bancária, utilizar o transporte urbano, aprender a utilizar o dinheiro do seu benefício para fazer compras de produtos de higiene pessoal e alimentos), estabelecer contatos com outras pessoas (e com familiares) e, se possível, um contato mais efetivo com a comunidade.

Desse modo, a instituição propõe um anteparo e a possibilidade de um vínculo inicialmente construído com o profissional por meio da transferência. Pode-se afirmar que a relação de transferência permite ao profissional medir e avaliar o contexto no qual o paciente está inserido, o seu grau de sofrimento e o seu grau de autonomia, ou seja, o que ele pode ou não fazer. Portanto, o sofrimento e os problemas do sujeito são dirigidos ao profissional que o atende e com o qual simultaneamente estabelece uma relação de confiança (conforme as psicanalistas e gerentes do CAPS Integração e Esperança, respectivamente (Bichara \& Palmieri 2007: 231)).

No CAPS Esperança, $60 \%$ dos profissionais eram psicanalistas lacanianos. Eles estavam orientados pelas suas análises e pela sua formação em psicanálise. Contudo, a clínica psicanalítica não era transposta ao CAPS, mas uma ética da psicanálise lacaniana aplicada à instituição, ou melhor, aplicada à terapêutica orientava as práticas (Mena 2009: 4). Isto faz dessa prática algo que se assemelha mais a uma análise institucional ou transferência institucional: na medida em que o grupo é estruturado como uma experiência de linguagem, ele pode ser um grupo sujeito e não se aprisionar em seus próprios discursos, segundo o psicanalista e filósofo francês Felix Guattari (1985: 92, 2004: 76). Em decorrência disso, os profissionais não procuram entender as alucinações ou enigmas dos sujeitos. Eles criam estratégias de ação, em equipe, para estabelecer um controle analítico (dos sintomas), um controle político (criação de formas alternativas ao internamento) e um controle ético (no sentido em que a intervenção terapêutica é formulada a partir do saber que o paciente possui sobre o seu sofrimento, seus desejos e suas necessidades). Assim, as práticas de cuidados não eram uma imposição, mas uma relação de consenso e participação, que implica em vínculos de responsabilidade e de obrigação. 


\section{AS PRÁTICAS DEMOCRÁTICAS}

Pretendo expor neste tópico como os usuários da instituição, considerados cidadãos de direito, independentemente do seu diagnóstico, passam por um controle incessante modulado por uma relação terapêutica caracterizada por vínculos interpessoais. Essa relação de proximidade permite ao profissional detectar (por meio da escuta terapêutica ou pela observação de um comportamento ou sintoma) indícios sobre a forma idiossincrática pela qual o paciente manifesta sua crise ou sofrimento. Esse cálculo aciona uma avaliação coletiva que produz estratégias de intervenções preventivas. A questão central, parece-me, é descrever como os discursos acerca das práticas democráticas inventam um modo tático de convencimento, condução, gestão e sugestão dos pacientes. Porém, a ideia aqui não é verificar se a doença se ajusta ou desvia dos regulamentos psiquiátricos, mas expor o jogo de argumentação dos profissionais sobre aquilo que eles pensam e fazem.

Segundo uma psicóloga do CAPS, a atuação política dos atores é denominada de "exercício da democracia nas práticas terapêuticas" ${ }^{\prime \prime}$. Essa forma de exercício democrático mobiliza tanto os profissionais quanto os pacientes a participarem dos espaços coletivos de formulação das normas institucionais. Ao mesmo tempo, os cidadãos portadores de sofrimento psíquico colaboram, como em uma aliança política, com a formulação das atividades que constitui o seu contrato terapêutico. Essa forma de funcionamento, que permite a existência de práticas democráticas, foi denominada de cogestão, visto que possibilita relações de negociação, ou seja, relações que procuram o consenso como o fundamento para estabelecer uma decisão. Em outras palavras, a lógica da cogestão, que se propaga para todas as relações e situações, é uma noção que organiza as relações de forma horizontal.

Essa lógica de funcionamento operacionaliza as relações entre os atores (usuários, gestores e profissionais) e produz vínculos de comprometimento para resolver os problemas, para solucionar os conflitos e para criar um novo modelo de assistência à saúde mental diferente do modelo de confinamento hospitalar. O confinamento ou a internação provocam o isolamento do paciente. No contexto de crise (contexto de sofrimento intenso do paciente que necessita de cuidados emergenciais), os profissionais acionam a internação hospitalar (como a última alternativa, depois de acionadas outras intervenções, a exemplo, aumentar a medicação e acolher o paciente no leito noite do CAPS), pois o tratamento nos leitos de enfermarias psiquiátricas se resume à alta dosagem de medicação e contenção física (amarrar o paciente no leito). No hospital, adicionalmente, o paciente será tratado por outros profissionais que desconhecem o seu caso clínico (a sua história de vida, a sua singularidade ou as suas idiossincrasias). Entretanto, a internação não é vista como um corte nas relações (Strathern 2011: 14), mas como uma suspensão dos vínculos heterogêneos que esse sujeito fabrica na instituição cotidianamente.

O modelo de funcionamento da cogestão possibilita aos atores tomarem parte de uma experiência comum, ou seja, resgatar o comum como um conceito político. Isto, como afirmou o filósofo e sinólogo francês François Jullien (2009: 43), permite- nos avaliar como as relações compartilhadas conectam as pessoas por meio de um sentimento de pertencimento a um coletivo. Os atores são assim implicados em uma relação de responsabilidade, doação e obrigação em uma tarefa ou em uma função. Desse modo, os desdobramentos dos seus vínculos assumem 
o caráter de um modelo familiar, porém não de uma forma fixa ou imutável, visto que os atores decidem quais vínculos serão compartilhados ${ }^{8}$.

Para os profissionais, na instituição o paciente aprende a lidar com novas situações e produz, ao mesmo tempo, subjetividade, autonomia e "uma nova forma de estar no mundo". O manejo da cidadania se materializa nas intervenções dos profissionais que procuram acompanhar os pacientes em sua nova forma de viver fora do hospital psiquiátrico. No CAPS Esperança, os profissionais não negam a existência dos sofrimentos (caracterizados pelos sintomas da psicose como alucinações, agitação e agressividade), mas investem na capacidade dos sujeitos em estabelecer novas normas. Assim como afirmou Canguilhem (1966: 196-197), ao analisar os conceitos de normal e de patológico, a saúde não está relacionada com a normalidade, mas sim com a capacidade de ser normativo, ou seja, de se adaptar e instituir novas regras. As intervenções acontecem quando o sujeito possui alguma dificuldade na interação social que tem como efeito um sofrimento. Deste modo, as estratégias e táticas de cuidados incidem sobre o jogo da resolução das queixas (ou problemas) dos sujeitos. Os profissionais procuram aliviar o sofrimento do paciente por meio de práticas como a escuta e o acolhimento.

O acolhimento é uma forma de cuidado. Sua prática depende de uma postura calculada, ou, nas palavras de uma psicóloga do CAPS, "temos que estar sensíveis para nos afetarmos pelo sofrimento do outro". Os profissionais assumem, na prática do acolhimento, uma postura ética de escutar tanto os pacientes quanto os demais profissionais que precisam de ajuda. No cotidiano das relações, essa prática viabiliza um "acesso ao paciente", ou seja, a aquisição de um saber para administrar o caso clínico. Como afirmam meus interlocutores, a prática da escuta terapêutica permite ao profissional adquirir informações para calcular a sua forma de atuação (ou de se comportar) e o modo como deverá agir em relação a um paciente que não está se sentindo bem ou que precisa de ajuda para resolver um problema. $\mathrm{Na}$ instituição, alguns espaços permitem que os profissionais fiquem próximos dos pacientes. Desse modo, eles podem observar de forma contínua os aspectos gerais de suas manifestações mórbidas e suas capacidades ou dificuldades em desenvolver as atividades propostas.

As relações e as atividades, no CAPS, são atravessadas por um poder clínico específico. Isso promove em seus efeitos a gestão de pessoas, ou melhor, o que Foucault (2003: 131) chamou de "administração dos corpos" e "gestão calculista da vida". Cabe lembrar que as possibilidades de ação passam necessariamente pelo consentimento dos sujeitos. Para adquiri-lo, as práticas são minuciosamente formuladas a partir das suas necessidades. A avaliação da eficácia das intervenções terapêuticas é feita a partir de um jogo de observação dos pacientes. Os sinais, os sintomas, os efeitos colaterais da medicação, os comportamentos agressivos, as agitações, o vestuário e a higiene pessoal são observados continuamente. Esse acompanhamento é feito por todos em qualquer espaço da instituição e também, em alguns casos, fora dela nas visitas domiciliares. 


\section{INFORMAÇÃO E ESCRITA: O REGISTRO DOS SUJEITOS}

As conexões estabelecidas em rede permitem aos atores partilharem de um sistema de comunicação baseado nas relações individuais o que, por sua vez, possibilita a circulação de informações de forma rápida e eficiente. $\mathrm{Na}$ instituição, os canais de comunicação podem ser observados em seus aspectos organizacionais, uma vez que, na maior parte do tempo, os profissionais conversam sobre os pacientes, discutem o caso clínico ou narram uma visita domiciliar. As informações compartilhadas permitem-lhes avaliar o seu posicionamento frente às reações dos sujeitos. $\mathrm{O}$ ato de evoluir é uma prática de atualização constante de todas as informações sobre o que acontece com os sujeitos. Desse modo, registra-se no prontuário todo o procedimento realizado, os exames médicos solicitados, as atividades das quais o paciente participa, as internações, sua história de vida, seu estado atual, as medicações utilizadas, as especificidades da manifestação de suas crises, a regularidade e a frequência com que vai até a instituição.

As práticas institucionais (a exemplo, a triagem, a escuta terapêutica e a observação do paciente) são exames que permitem colocar em funcionamento a obtenção de um saber. Foi o que Foucault chamou de prova psiquiátrica, a qual compõe "a vida de um indivíduo como tecido de sintomas patológicos" (Foucault 2006: 348). Nesse sentido, o sujeito é investido por um procedimento técnico-administrativo de controle permanente, no qual o discurso, o comportamento, a maneira de se vestir e determinado sentimento de sofrimento podem explicar um contexto de crise. Nesse caso, os procedimentos administrativos autorizam, ou melhor, fazem referência à possibilidade de existência da pessoa enquanto um sujeito classificado como doente. Os motivos para uma intervenção são as demandas transcritas em termos de sintomas, doença ou angústia.

Os sintomas são medicados. Para o epistemólogo e sociólogo francês Philippe Pignarre (2008), os neurolépticos ${ }^{9}$ não curam a esquizofrenia, mas aliviam os sintomas mais incômodos. No CAPS Esperança, os pacientes sempre conversam com os profissionais de sua miniequipe ou diretamente com o médico psiquiatra que cuida do seu caso. Conforme já notou Pignarre (2008a), é consenso entre os profissionais da área da saúde considerar os pacientes como casos clínicos. Foucault (2002: 159), já havia apontado anteriormente para a mesma questão, ou seja, a percepção dos indivíduos como um objeto descritível, mensurável, analisável, mantendo-os em suas singularidades e em suas capacidades particulares. Pode-se afirmar que a prescrição da medicação é feita pelo médico, mas está estritamente relacionada à escuta terapêutica e às informações que os profissionais adquirem por meio da transferência. Este saber possibilita a compreensão de como o paciente funciona com determinada medicação. Nesse sentido, ao falar de um efeito indesejado da medicação para o técnico em que confia, ele faz com que essa informação chegue ao médico, que acaba por modificar sua prescrição.

O funcionamento da terapêutica é marcado por micropoderes que organizam a dinâmica das relações no interior da instituição. No caso da medicação, as relações de poder operam por meio de um jogo de forças que permite ao médico apreender internamente o processo do adoecimento, a partir de um saber que o psiquiatra “imagina poder compreender dos fenômenos da loucura” (Foucault 2006: 373). Nesse processo, esta última é 
caracterizada como sofrimento; o uso do remédio possibilita a reprodução artificial desse estado, uma vez que produz efeitos nos corpos - efeitos em sua maioria indesejáveis, isto é, efeitos colaterais ${ }^{10}$ que afirmam para o sujeito a condição de doente. Em suas análises, Pignarre (2008b) observou os efeitos colaterais no uso da medicação psicotrópica. Para ele, estas medicações são utilizadas para sedar ou diminuir o nível de consciência dos pacientes com a intenção de controlar os comportamentos agitados e agressivos. O autor afirma que o "diagnóstico de esquizofrenia implica na prescrição de um neuroléptico, cujos efeitos colaterais fazem com que o paciente pareça cada vez mais com um esquizofrênico!" (Pignarre 2008b: 4). Nesse sentido, a prescrição de um neuroléptico não trataria o diagnóstico da psicose, somente aliviaria seus sintomas. $\mathrm{O}$ uso prolongado e contínuo deste último acarreta efeitos colaterais irreversíveis, como as discinesias tardias ${ }^{11}$ (Pignarre 2008c).

Os efeitos medicamente nocivos são provocados pela ação da intervenção médica fundada em sua racionalidade. Isto quer dizer que, em alguns momentos, as intervenções médicas podem produzir efeitos incontroláveis que sujeitam os indivíduos em um processo arriscado, que pertence ao domínio das probabilidades. No CAPS, o médico prescreve, com frequência, doses elevadas de medicação ao mesmo tempo em que prescreve outras que têm a função de inibir seus efeitos colaterais. Em outras palavras, estes últimos são tão frequentes que, na conduta médica, é comum seu cálculo antecipado, o que se traduz na prescrição concomitante ao antipsicótico, de um medicamento que irá inibir e/ou prevenir seus efeitos colaterais.

Uma interlocutora de pesquisa afirmou que os pacientes que recebem tratamento em instituições como os CAPS são mais medicados comparados à época em que esses residiam no hospital psiquiátrico. Quando questionado a este respeito, ele respondeu que os pacientes que foram ressocializados ${ }^{12}$, e são tratados na instituição, estariam atualmente em contato com pessoas e relações, algo antes impossível uma vez que eram confinados no hospital psiquiátrico ${ }^{13}$. Para meus interlocutores, o contato com a realidade social faria com que os pacientes necessitassem de mais medicações para evitar o sofrimento. Vemos aqui um sistema no qual a terapêutica é ordenada pelo uso da medicação, assim como os corpos dos sujeitos construídos e constituídos por essa relação química.

Nesta nova perspectiva, observada também pelo sociólogo francês Robert Castel, verifica-se uma atualização do conceito de biopoder. A emergência do uso de drogas psiquiátricas traz a ideia de "cura" a partir da "gestão dos riscos" (Castel 1983: 125). A prevenção (uma forma de rastrear os fatores que tornam algo provável de acontecer) materializa-se em práticas de vigilância e controle dos sintomas e dos comportamentos por meio de drogas psicoativas utilizadas para melhorar um mal-estar psíquico e não para o tratamento das doenças, uma prática na qual as pessoas não mais transitam entre estados normais e patológicos.

\section{RELACÕES DE PODER: A ESTRATÉGIA DO "ESTUDO DO CASO CLÍNICO"}

Para Foucault (1995: 248) as estratégias de poder operam um funcionamento tático na medida em que constituem formas de ação sobre ações possíveis. A racionalidade empregada no estudo do caso clínico tem por objetivo 
analisar as singularidades de cada sujeito e produzir modos de intervenção calculados que incidem sobre as condutas do usuário. Nesse sentido, o paciente (aquele sobre o qual o poder se exerce) é reconhecido pelos saberes que são produzidos sobre sua singularidade, ao mesmo tempo em que é mantido como um sujeito de ação, pois ele compactua com a relação de controle. A relação de poder não se mostra apenas pelo uso da violência, ela se manifesta pela aquisição dos consentimentos.

Os profissionais observam e analisam os efeitos terapêuticos nos corpos, nos gestos e nos comportamentos daqueles que são cuidados. Deste modo, promove-se um controle que exige sua participação, firmada pelo contrato terapêutico, isto é, por um pacto democrático continuamente negociado no interior da relação de cuidado. Essa aliança, firmada no processo terapêutico, implica na responsabilização do paciente em cumprir as obrigações determinadas pelo vínculo de transferência com o profissional. As relações de poder são visualizadas no exercício de práticas como a escuta e a observação permanente dos sujeitos. Nesse sentido, as queixas dos pacientes são caracterizadas como sofrimento e a medicalização reproduz esse mal-estar de uma forma artificial, já que o remédio produz, muitas vezes, efeitos colaterais. A forma de prescrição no CAPS Esperança reassume o discurso da psiquiatria clássica, pois investe nos sintomas. Observa-se que os profissionais, a instituição, as práticas de cuidados e o controle, moldam-se às particularidades de cada sujeito tratado. Os profissionais avaliam continuamente a experiência de interação do paciente com a medicação, sendo que o objetivo dessa prática é calcular a eficácia do controle medicamentoso.

O comportamento do usuário e suas idiossincrasias constituem um saber acumulado e permanente sobre o indivíduo. Ao descrever o estado geral e as características dos pacientes, os profissionais tornam o corpo visível por meio da escrita. $O$ acesso às informações, segundo os interlocutores dessa pesquisa, ajuda em alguns casos, como, por exemplo, na identificação de um sintoma indicador de um estado de crise. A partir disso, pode-se afirmar o caráter virtual do cálculo terapêutico, que prevê uma situação por intermédio da experiência anteriormente descrita e registrada sobre a individualidade dos pacientes. Assim, o procedimento da escrita e da documentação das informações permite aos profissionais um controle preventivo. A prevenção psiquiátrica materializa-se em práticas que permitem antecipar as urgências (crises). Em decorrência disso, os profissionais estavam sempre atentos e/ ou vigilantes para serem afetados por algo "inusitado ou inesperado" ou por comportamentos imprevisíveis, de “passagem ao ato" e agressividade.

Para Castel (1987: 125), a imputação de periculosidade é estabelecida por um cálculo de probabilidade intuitiva do profissional. Ao avaliar um paciente, este último elabora possibilidades de correlação entre os sintomas atuais e um comportamento futuro. Desse modo, pensar a probabilidade é diferente de afirmar a qualidade de ser perigoso como imanente ao paciente (Castel 1983: 120). No CAPS, havia situações de risco, como o momento da pré-crise (momento que aparecem os sintomas da crise), em que as estratégias preventivas acionavam medidas de controles, por vezes, disciplinares (a exemplo, contensões químicas - por meio do uso de medicamentos - e físicas). Isso acontecia quando se detectava o risco de um comportamento agressivo. As intervenções produzidas a partir de um conhecimento acerca da regularidade dos sintomas têm por objetivo antecipar um evento indesejável. 
O ajuste (ou atualização) da medicação é uma das intervenções que fazem parte do cotidiano dos pacientes no CAPS Esperança. O médico prescreve o remédio a partir de um saber elaborado sobre a experiência de interação do sujeito com a substância química. Essa forma de medicar necessita de sua participação e implicação. Segundo os profissionais, essa relação de colaboração é importante para precisar a dose adequada da medicação, o que Pignarre denominou de "arte da dosagem" (2006: 190). O medicamento é absorvido por receptores ${ }^{14}$ de dopamina existentes no cérebro. Para os especialistas em neuropsicofarmacologia, Moreira \& Guimarães (2007:67), a medicação antipsicótica provoca uma desaceleração das células de dopamina. Essas células são responsáveis pela regulação e pelo controle dos movimentos musculares, pela cognição, pela capacidade de sentir as sensações de prazer, ânimo e motivação. A medicação antipsicótica promove uma sedação e um controle dos sintomas, substituindo terapias como a lobotomia devido à contenção química que promove. Ela foi igualmente indispensável para sustentar o processo de ressocialização e a Reforma Psiquiátrica.

Para os interlocutores dessa pesquisa, a psicanálise ensina o profissional a escutar as indicações que cada paciente elabora como solução para seu sofrimento. Segundo uma psicóloga do CAPS Esperança, a atuação do profissiona/ tem a intenção de "permitir que o sujeito psicótico encontre seu próprio tratamento, inventando suas soluções particulares" (Bedin 2009: 26). O sintoma é aí considerado como uma elaboração particular do sujeito, visto que ele é ligado indissoluvelmente a ele e considerado uma propriedade exclusiva da pessoa - como afirmou, em sua análise sobre a "medicina dos brancos", o psicanalista egípcio Tobie Nathan (1995: 50), coordenador do centro de etnopsiquiatria Georges Devereux. Para os profissionais do CAPS, o paciente está contido de forma particular em seu sintoma. Eis o sujeito que, segundo Lacan, é "como um sintoma que nunca se dissolve" (apud Safatle 2001). No CAPS, tanto os médicos psiquiatras quanto os profissionais influenciados ou não pela psicanálise lacaniana concordam que o sintoma deve ser proferido pelo paciente e, nesse sentido, ele é considerado uma responsabilidade do sujeito. Os profissionais do CAPS são obrigados a aprender sobre a complexidade de seus pacientes. Isso os transformam em tradutores de fatos que compõem versões de existências complexas. 


\section{NOTAS}

1 Este artigo apresenta os resultados da minha pesquisa de mestrado defendida no programa de Pós-Graduação em Antropologia Social da Universidade Federal de São Carlos (Sartori 2010).

2 O Serviço de Saúde Cândido Ferreira (SSCF) (ou, apenas, Cândido como os meus interlocutores de pesquisa se referem à instituição) é uma instituição pública regida pelo direito privado (Sartori 2011a).

3 A respeito da lógica da cogestão e da forma de funcionamento do convênio firmado entre o Cândido Ferreira e a Prefeitura de Campinas, ver Sartori (2011a).

4 Paciente é a forma como os profissionais do CAPS nomeiam as pessoas assistidas pela instituição, palavra esta utilizada para designar uma pessoa de modo não específico, uma vez que quando se referem a um paciente conhecido pela equipe, o fazem normalmente pelo nome. Utilizarei o substantivo paciente no singular como um dado de campo que remete aos sujeitos tratados de forma geral.

5 A Reforma Psiquiátrica é um assunto discutido em grande parte das obras sobre saúde mental no Brasil, ver a respeito Amarante (1995a, 1995b), Vasconcelos (2002) e Delgado et al. (2007).

6 A equipe está previamente dividida em três miniequipes de referência. Cada uma delas é responsável por um número de pacientes e por um número de instituições de saúde localizadas no distrito leste.

7 Entrevista concedida pela psicóloga Geórgia, atual gerente do CAPS Esperança, para o programa de rádio "em pauta a saúde mental" do Ponto de Cultura Maluco Beleza (ver: www.radiomalucobeleza.org.br).

8 Um exemplo da produção de vínculos e da produção de relações familiares no Serviço Residencial Terapêutico, ver Sartori (2011b).

9 O neuroléptico é um tipo de medicamento indicado para o tratamento dos sintomas da psicose. http://www.psicosite.com.br/far/anp/ haldol.htm.

10 Os efeitos colaterais observados costumam ser: salivação excessiva, tremores, pele oleosa, discinesia. Também podem ocorrer efeitos sobre o sistema motor, como: rigidez muscular, inquietação, dificuldade de ficar parado, vontade de andar e mexer com as pernas, mesmo estando parado.

11 A discinesia tardia (DT) é um efeito extrapiramidal causado por neurolépticos, caracterizada por movimentos involuntários, anormais e repetitivos localizados principalmente na região orofacial, tronco, extremidades inferiores e superiores. A DT acomete ao menos $20 \%$ dos indivíduos, com taxas de incidência para novos casos de aproximadamente 3 a $5 \%$ ao ano. Essa incidência ocorre de maneira cumulativa e chega a 30\% entre os idosos expostos ao uso crônico de neurolépticos (Soares 1998).

12 Processo de Ressocialização foi caracterizado pela prática da desinstitucionalização dos pacientes que residiam nos hospitais psiquiátricos.

13 Os dados epidemiológicos disponibilizados pelo Datasus revelam que no período entre 1995 e 2005 ocorreu um aumento de $15 \%$ na distribuição de psicotrópicos e um aumento significativo dos serviços comunitários. Em uma década, diminuíram em $26,7 \%$ os gastos destinados à saúde mental. Aumentaram os serviços comunitários e reduziram $41 \%$ do número de leitos em hospitais psiquiátricos. Em 1995, as internações psiquiátricas representavam 95,5\% dos gastos, enquanto em 2005 esse número representava 49\% (Andreoli et al. 2007).

14 Os receptores seriam células que compõem o córtex cerebral, sendo este, por sua vez, responsável pela representação, pelo entendimento e pela razão. 


\section{REFERÊNCIAS BIBLIOGRÁFICAS}

ANDREOLI, S. B. et al. 2007. "Is psychiatric reform a strategy for reducing the mental health budget? The case of Brazil". Revista Brasileira de Psiquiatria 29(1).

AMARANTE, P. 1995a. "Novos Sujeitos, Novos Direitos: O Debate em Torno da Reforma Psiquiátrica". Cad. Saúde Pública 11(3).

2009. Luta por reconhecimento: a gramática moral dos conflitos sociais. São Paulo: Ed. 34.. 1995b. Loucos pela vida - a trajetória da reforma psiquiátrica no Brasil. Rio de Janeiro: Fiocruz.

BALANDIER, G. 1969. Antropologia Política. São Paulo: Diefel/Edusp.

BEDIN, B. V. 2009. Reflexões sobre as práticas grupais nos Centros de Atenção Psicossocial: uma interface com a clínica lacaniana da psicose. Dissertação. Campinas, SP: Universidade Estadual de Campinas. Faculdade de Ciências Médicas.

BICHARA, P. F \& PALMIERI, T. C. 2007. “O acompanhamento de Residências Terapêuticas pela equipe de um Hospital-Dia". In E. Merhy \& H. Amaral (orgs.) A Reforma Psiquiátrica no Cotidiano II. São Paulo: Hucitec.

BIEHL, João. 2008. "Antropologia do devir: psicofármacos - abandono social - desejo". Revista de Antropologia 51(2) BIONDI, K. 2010. Junto e Misturado: uma etnografia do PCC. São Paulo: Terceiro Nome.

BRASIL. 2002. “Portaria do Ministério da Saúde N. 336-02". Disponível em: http://portal.saude.gov.br/portal/arquivos/ pdf/Portaria\%20GM\%20336-2002.pdf.

CARDOSO, M. 1999. Médicos e clientela: da assistência psiquiátrica à comunidade. São Carlos: UFSCAR.

2009. Luta por reconhecimento: a gramática moral dos conflitos sociais. São Paulo: Ed. 34.. 2002. “Psiquiatria e Antropologia: notas sobre um debate inconcluso". ILHA Revista de Antropologia 4(1).

CASTEL, R. 1983. “De la dangerosité au risque". In Actes de la recherche en sciences sociales. 47-48: 119-127

2009. Luta por reconhecimento: a gramática moral dos conflitos sociais. São Paulo: Ed. 34.. 1987. A gestão dos riscos: da psiquiatria à pós-psicanálise. Rio de Janeiro: Francisco Alves.

CANGUILHEM, G. 1966. O Normal e o Patológico. Rio de Janeiro: Graal.

CHAVES, C. 2003. Festa na Política: uma etnografia da modernidade no sertão (Buritis, MG). Rio de Janeiro: Relume-Dumará.

DELEUZE, G. 2007a. Conversações. São Paulo: Ed. 34.

2009. Luta por reconhecimento: a gramática moral dos conflitos sociais. São Paulo: Ed. 34.. 2007b. Nietzsche. Lisboa: Edições 70.

DELGADO, P. G. G. et al. 2007. “Reforma Psiquiátrica e política de saúde mental no Brasil”. In M. F. de Mello, A.A.F. de Mello \& R. Kohn (orgs.) Epidemiologia da saúde mental no Brasil. Porto Alegre: Ed. Artmed. 
DIAS, M. K. 2007. Centro de Atenção Psicossocial: do modelo institucional à experiência social da doença. Tese de Doutorado. Campinas, SP: Unicamp.

DUARTE, L. F. D. 1986. Da Vida Nervosa nas Classes Trabalhadoras. Rio de Janeiro: Zahar.

2009. Luta por reconhecimento: a gramática moral dos conflitos sociais. São Paulo: Ed. 34.. 1994. “A outra saúde: mental, psicossocial, físico-moral?" In P.C. Alves (org.) Saúde e Doença: um olhar antropológico. Rio de Janeiro: Fiocruz.

2009. Luta por reconhecimento: a gramática moral dos conflitos sociais. São Paulo: Ed. 34.. 2000. “Individuo e pessoa na experiência da doença". Revista Ciência e Saúde Coletiva 8(1): 173-183.

FAVRET-SAADA, J. 2005. "Ser afetado, de Jeanne Favret-Saada". Cadernos de Campo 3: 155-161.

FOUCAULT, M. 1995. “O Sujeito e o Poder". In H. Dreyfus \& P. Rabinow Michel Foucault, uma trajetória filosófica: para além do estruturalismo e da hermenêutica. Rio de Janeiro: Ed. Forense Universitária.

2009. Luta por reconhecimento: a gramática moral dos conflitos sociais. São Paulo: Ed. 34.. 2002. Vigiare Punir: nascimento da prisão. Rio de Janeiro: Ed. Vozes.

2009. Luta por reconhecimento: a gramática moral dos conflitos sociais. São Paulo: Ed. 34.. 2003. História da Sexualidade: a vontade de saber. São Paulo: Ed. Graal.

2009. Luta por reconhecimento: a gramática moral dos conflitos sociais. São Paulo: Ed. 34.. 2006. O poder psiquiátrico. São Paulo: Martins Fontes.

2009. Luta por reconhecimento: a gramática moral dos conflitos sociais. São Paulo: Ed. 34.. 2010. “A tecnologia política dos indivíduos". In Ditos e Escritos V. Ética, sexualidade, política. Rio de Janeiro: Editora Forense Universitária

GOLDMAN, M. 2006. Como funciona a democracia: uma teoria etnográfica da política. Rio de Janeiro: Ed. 7Letras.

GUATTARI, F. 1985. Revolução Molecular: pulsações políticas do desejo. São Paulo: Ed. Brasiliense.

2009. Luta por reconhecimento: a gramática moral dos conflitos sociais. São Paulo: Ed. 34.. 2004. Psicanálise e Transversalidade: ensaios de psicanálise institucional. Aparecida: Editora Ideias e Letras.

JULLIEN, F. 2009. O Diálogo entre as culturas: do universal ao multiculturalismo. Rio de Janeiro: Ed. Zahar.

LIENHARDT, G.1958. “The Wertern Dinka”. In J. Midleton \& D. Tait, D. Tribes Without Rulers. Studies in African Segmentary Systems. Londres: Routledge and Kegan Paul.

LOUGON, M. 1987. Os Caminhos da mudança. Alienados, alienistas e as desinstitucionalização da Psiquiatria. Tese de Doutorado. Rio de Janeiro: Museu Nacional/UFRJ.

MARQUES, A. C. 2002. Intrigas e questões: vingança de família e tramas sociais no sertão de Pernambuco. Rio de Janeiro: Relume-Dumará.

2003. "Política e questão de família". Revista de Antropologia 45(2): 417-442. 
MENA, Luiz. 2009. Contribuições das 'Entrevistas do momento atual' para a psicanálise aplicada à terapêutica. Disponível em: <http://www.clin-a.com.br>. Acessado em: 5/1/2011.

MONNERAT, S. 2009. Trajetórias, acusações e sociabilidade: uma etnografia em um Centro de Convivência para pacientes psiquiátricos. Dissertação de Mestrado. Rio de Janeiro: PPGAS-Museu Nacional/UFRJ.

2010. "Atenção à Saúde Mental: estudo comparativo entre um serviço público e um particular". In // Encontro Internacional de Ciências Sociais: as Ciências Sociais e os desafios para o século XXI. Pelotas.

MOREIRA, F. A. \& GUIMARÃES, F. S. 2007. "Mecanismos de ação dos antipsicóticos: hipóteses dopaminérgicas". Revista de medicina de Ribeirão Preto 40(1): 63-71.

NATHAN, T. 1995. "Le Médecins et le Charlatan". In T. Nathan \& I. Stenger Médecins et Sorciers. Paris: Les Empêcheurs de Penser en Rond.

NIETZSCHE, F. 2004. Genealogia da Moral. São Paulo: Companhia das Letras.

PALMEIRA, M. 1992. "Voto: racionalidade ou significado?". Revista Brasileira de Ciências Sociais 7(20): 26-30.

1996. "Política, facções e voto". In M. Palmeira \& M. Goldman (orgs.) Antropologia, voto e representação política. Rio de Janeiro: Ed. Contra Capa.

PASSETTI, E. 2003. Anarquismo e sociedade de controle. São Paulo: Ed. Cortez.

PERELBERG, R. J. 1980. As fronteiras do silêncio. Um estudo de desvio e ritualização. Rio de Janeiro: Adrianú.

PIGNARRE, P. 2006. “Avoir besoin que les gens pensent". Multitudes 23.

2008a. "Médicaliser/démédicaliser: développer l'expertise des patients". Cliniques méditerranéennes 77. Disponível em : http://www.pignarre.com/article.php.

2008b. "Os pacientes pouco sedados são mais "incômodos" para a equipe de enfermagem?". Disponível em: http://www.pignarre.com/article.php.

.2008c. "O futuro ameaçador da indústria farmacêutica". Disponível em: http://www.pignarre.com/article.php.

SAFATLER, Vladimir. 2001. “Clínica, estética e reconhecimento: uma entrevista”. Acheronta 14.

SARTORI, L. 2010. O Manejo da Cidadania em um Centro de Atenção Psicossocial. Dissertação de Mestrado. São Carlos: Programa de Pós-Graduação em Antropologia Social da Universidade Federal de São Carlos.

2011a. "O Convênio de Cogestão: política, instituição e gestão pública". R@U: Revista de Antropologia Social dos Alunos do PPGAS-UFSCar 3(1): 385-392.

2011b. "A relação familiar na gestão estatal de pacientes psiquiátricos ressocializados". In IX Reunião de Antropologia do Mercosul. Curitiba, PR.

SILVA, M.B.B. 2005. "Atenção Psicossocial e Gestão de Populações: sobre os discursos e as práticas em torno da responsabilidade no campo da saúde mental". Physis: Revista de Saúde Coletiva 15(1): 127-150. 
2007. “O Técnico de Referência no Centro de Atenção Psicossocial: uma nova especialidade no campo da saúde mental?". Revista Vivência 32.

2009. “O Caso 'Damião Ximenes': saúde mental e direitos humanos". Revista Série Anis IX(67).

SOARES, K. 1998. “Tratamento da Discinesia Tardia induzida por neurolépticos”. Psychiatry on line Brasil. Disponível em: http://www.polbr.med.br/ano98/discines.php.

STRATHERN, M. 2011 [1996]. “Cortando a Rede". Revista Ponto Urbe 5.

SWARTZ, M. J.; TURNER; V. W. \& TUDEN, A. 1966. Political Anthropology. Chicago: Aldine Publishing Company.

VASCONCELOS, E. M. 2002. Saúde mental e serviço social. O desafio da subjetividade e da interdisciplinaridade. São Paulo: Ed. Cortez.

VENÂNCIO, A.T.A. 1990. Sobre a Nova Psiquiatria no Brasil: Um Estudo de Caso do Hospital-Dia do Instituto de Psiquiatria. Dissertação de Mestrado. Rio de Janeiro: PPGAS-Museu Nacional/UFRJ

VEYNE, P. 2001. Foucault: Seu Pensamento, sua pessoa. Rio de Janeiro: Ed. Civilização Brasileira.

VILLELA, J.L.M. 2004. O Povo em Armas: Violência e Política no Sertão de Pernambuco. Rio de Janeiro: Relume Dumará.

2009. “Família Como Grupo? Política como agrupamento?". Revista de Antropologia 52: 201-246.

2010a. "Apresentação". In K. Biondi Junto e Misturado: uma etnografia do PCC. São Paulo: Ed. Terceiro Nome.

2010b. “Moral da Política e Antropologia das Relações de Poder no Sertão de Pernambuco". Revista Lua Nova 79: 163-199. 


\section{O Manejo da Cidadania e a Democracia do Cuidado}

\section{RESUMO}

Neste artigo procuro expor o modo de funcionamento de uma nova tecnologia de cuidado colocada em prática pelos profissionais do Centro de Atenção Psicossocial (CAPS) Esperança, na região leste de Campinas - SP. Para isso, apresento as reflexões dos profissionais acerca de suas práticas e descrevo as relações democráticas que orientam a atuação do profissional na invenção de cuidados, que não se resumem às intervenções médicas. Além disso, analiso como se configura a dinâmica de funcionamento das práticas democráticas e o modo de organização do cuidado operacionalizado pela prática da escuta terapêutica e pelo uso da medicação. Por fim, descrevo como os profissionais conceitualizam suas experiências ao explicar a participação dos usuários como parceiros na elaboração dos seus projetos terapêuticos.

PALAVRAS-CHAVE: práticas de cuidado; relações de poder; política; CAPS; Campinas.

\section{Citizenship Management and the care democracy}

\section{ABSTRACT}

This article shows a new technology of care functions and how it is practiced by professionals of the Centro de Atenção Psicossocial (CAPS) Esperança, in the east region of the city of Campinas, in the state of São Paulo. Analyses made by professionals about their practices and democratic relations that guide the actions of these professionals in inventing care practices, that are not only medical interventions, are described. I also analyze the dynamic of functioning of the democratic practices and the way of organization of care operated by the therapeutic listening practice and by the use of meditation. At last, I describe how professionals conceptualize their experiences as they explain the participation of users as partners in the elaboration of their therapeutic projects.

KEYWORDS: care practices; power relations; politics; CAPS; Campinas.

Recebido em: 24/09/2011

Aprovado em: 31/01/2012 